University of Nebraska - Lincoln

DigitalCommons@University of Nebraska - Lincoln

Sociology Department, Faculty Publications

Sociology, Department of

March 2006

\title{
Family, Community, and School Influences on Resilience among American Indian Adolescents in the Upper Midwest
}

Teresa D. LaFromboise

Stanford University

Dan R. Hoyt

University of Nebraska-Lincoln, dhoyt2@unl.edu

Lisa Oliver

San Jose State University

Les B. Whitbeck

University of Nebraska-Lincoln, Iwhitbeck2@unl.edu

Follow this and additional works at: https://digitalcommons.unl.edu/sociologyfacpub

Part of the Sociology Commons

LaFromboise, Teresa D.; Hoyt, Dan R.; Oliver, Lisa; and Whitbeck, Les B., "Family, Community, and School Influences on Resilience among American Indian Adolescents in the Upper Midwest" (2006). Sociology Department, Faculty Publications. 26.

https://digitalcommons.unl.edu/sociologyfacpub/26

This Article is brought to you for free and open access by the Sociology, Department of at DigitalCommons@University of Nebraska - Lincoln. It has been accepted for inclusion in Sociology Department, Faculty Publications by an authorized administrator of DigitalCommons@University of Nebraska - Lincoln. 
Published in Journal of Community Psychology 34:2 (March 2006), pp. 193-209;

doi 10.1002/jcop.20090 Copyright @ 2006 Wiley Periodicals, Inc. Used by permission.

http://www3.interscience.wiley.com/journal/32213/home

Corresponding author: Teresa D. LaFromboise, School of Education, Stanford University, 485 Lasuen Mall, Stanford, CA 94305-3096; email LaFrom@stanford.edu

\title{
Family, Community, and School Influences on Resilience among American Indian Adolescents in the Upper Midwest
}

\author{
Teresa D. LaFromboise \\ Stanford University \\ Dan R. Hoyt \\ University of Nebraska-Lincoln \\ Lisa Oliver \\ San Jose State University \\ Les B. Whitbeck \\ University of Nebraska-Lincoln
}

\begin{abstract}
This study examines resilience among a sample of American Indian adolescents living on or near reservations in the upper Midwest. Data are from a baseline survey of 212 youth (115 boys and 97 girls) who were enrolled in the fifth through eighth grades. Based upon the definition of resilience, latent class analyses were conducted to identify youth who displayed prosocial outcomes $(60.5 \%)$ as opposed to problem behavior outcomes. A measure of family adversity was also developed that indicated only $38.4 \%$ of the youth lived in low-adversity households. Defining resilience in the context of positive outcomes in the face of adversity, logistic regression was used to examine the predictors of prosocial outcomes among youth who lived in moderate- to high-adversity households. The analyses identified key risk and protective factors. A primary risk factor appeared to be perceived discrimination. Protective factors were from multiple contexts: family, community, and culture. Having a warm and supportive mother, perceiving community support, and exhibiting higher levels of enculturation were each associated with increased likelihood of prosocial outcomes.
\end{abstract}


Conditions on American Indian reservations today continue to demand a high degree of resourcefulness, competence, and flexibility. American Indians live in a society in which they must constantly adjust to the demands of their cultures and White American culture (LaFromboise, Coleman, \& Gerton, 1993). The stressors associated with this adjustment are particularly notable for youth. American Indian adolescents must learn to negotiate the "shifting requirements of multiple social and cultural systems as they are growing up" (Beauvais, 2000, p. 2). While living on reservations may expose youth to more poverty and fewer economic opportunities, it may also provide protective elements. For example, urban American Indian youth may well experience greater stress in daily living than their relatives on the reservation because it is difficult for them to access social support networks, such as extended family networks that are more readily available on reservations (LaFromboise \& Dizon, 2003). The reservations have been the base for another important component of resilience, the continuity and revival of American Indian culture and traditions (Goodluck, 2002).

Resilience in the face of adversity is not new to American Indian tribes. They have survived genocidal practices directed toward them, including a massive redistribution of people away from their homelands and the imposition of the reservation system. They withstood drastic changes in sociopolitical, cultural, and physical environments and the added stress from oppression and hostility. Through it all, many were able to adapt and overcome adverse circumstances. Although the term "resilience" has only recently been linked with Native people, the meaning of the term has been applied and practiced among American Indians for centuries. James Clairmont, a Lakota spiritual elder, expresses how the concept of resilience is inherent in his tribal culture: "The closest translation of 'resilience' is a sacred word that means 'resistance' . . . resisting bad thoughts, bad behaviors. We accept what life gives us, good and bad, as gifts from the Creator. We try to get through hard times, stressful times, with a good heart. The gift [of adversity] is the lesson we learn from overcoming it" (Graham, 2001, p. 1). It is important that research address the potential protective mechanisms that American Indian people and American Indian communities may provide to their youth rather than simply advancing deficit hypotheses (LaFromboise, Trimble, \& Mohatt, 1990). This research will examine resilience in the context of American Indian youth living on or near reservations and examine the factors that predict resilient outcomes in this high-risk population. We will assess how to best measure resilience and then systematically examine individual, family, and cultural predictors of resilience.

\section{Resilience}

Resilience has been defined in many different ways. Many views of resilience include metaphors associated with adaptability despite adverse circumstances or obstacles (Klarreich, 1998). All resilience definitions include the capacity to face challenges and to become somehow more capable despite adverse experiences. Most definitions emphasize that resilience is a process, rather than a fixed constitutional attribute, influenced by everyday decisions (Masten, 2001). According to this interpretation, resilience is conceptualized as a protective mechanism that modifies an individual's response to risk situations and operates at critical points during one's life (Newcomb, 1992). People who display resilient adaptation become stronger by learning new skills, developing creative ways of coping, and meeting and overcoming life's challenges (Luthar \& Zelazo, 2003). All of their experiences are viewed as educational because they contribute to one's growth in ability to deal with future problems. 
How youth cope with stressors varies across domain, development, and context. Particular characteristics rarely serve exclusively as risk or protective functions. Resilience factors generally fall into the following areas: (a) intrapersonal, (b) interpersonal, and (c) community, with culture shaping the person-in-environment interaction and thereby influencing all three perspectives (Delgado, 1995). Exposure to multiple protective or resilience factors can increase one's chance of competent social adjustment because it indirectly moderates the effects of risk exposure (Rutter, 1990).

\section{American Indian Resilience}

The recent history of American Indians in the United States has been associated with a number of dramatic and distinctive risk factors, including acculturation stress, repeated traumatic loss, poverty, social disorganization, political disempowerment, high rates of school dropout, alcohol abuse, inhalant abuse, chronic health conditions, and corresponding decline in resources, opportunities, and support (Appleton \& Dykeman, 1996; Blum, Potthoff, \& Resnick, 1997; Howard, Walker, Walker, Cottler, \& Compton, 1999; Kumpfer \& Alvarado, 1995; Nelson, Moon, Holtzman, Smith, \& Siegel, 1996; Office of Juvenile Justice and Delinquency Prevention, 1995). The likelihood of youth developing problems increases rapidly as the number of risk factors increases in comparison with the number of protective factors (Dunst \& Trivette, 1994). Yet, despite these formidable risks, many American Indian youth do become engaged in prosocial activities and successfully avoid problem behaviors. It is the presence of these positive outcomes, in the face of substantial adversity, that points to the resilience of American Indian youth.

There is a paucity of research on American Indian resilience. In fact, our review of the numerous works addressing resilience, found few empirical studies on resilience that focused solely on the American Indian population (Graham, 2001; Long \& Nelson, 1999) and relatively few that even addressed it indirectly (Miller-Heyl, MacPhee, \& Fritz, 1998; Pharris, Resnick, \& Blum, 1997). There has, however, been emerging conceptual development as to what would comprise resilience in this context (Cross, 1998; Goodluck \& Willeto, 2004; Heavy Runner \& Marshall, 2003; LaFromboise, Oliver, \& Hoyt, in press; Montgomery, Miville, Winterowd, Jefferies, \& Baysden, 2000). The contributions of these authors suggest the importance of community, family, and general Native cultural values as each being a critical element in the resilience and well-being of the youth.

\section{Predictors of Resilience}

A number of individual, family, and community characteristics are likely to contribute to resilient outcomes for youth. At the individual level, these include gender, positive self- esteem, and an active engagement in one's culture. At the family level, these would include family structure and parental support. At the community level, there are both positive community supports and risk factors, such as poverty and discrimination.

Risk for susceptibility to emotional distress, protection from situations of risk, and ways of responding to adversity may be gender-based during adolescence (Gardano, 1998; Fergusson \& Horwood, 2001). For example, Turner, Norman, and Zunz (1995) report that boys may be at risk when there are extreme levels of interdependence within the family, whereas girls may be at risk when there are extreme levels of independence or disengagement in family interactions. Girls tend to self-destruct with quiet, disturbed behaviors rather than act out with externalized behaviors as boys do. 
The social and emotional demands of adolescence may be particularly trying for American Indian girls. They frequently experience feelings of hopelessness (Blum, Harmon, Harris, Bergeisen, \& Resnick, 1992), become victims of violent behavior (e.g., battery, rape, sexual assault, or incest) (Fleming \& Manson, 1990), have high teen pregnancy rates (Blum et al., 1992), and undergo suicide-related hospitalizations more frequently than American Indian boys do (LaFromboise \& Howard-Pitney, 1995). These gender-based outcomes indicate that American Indian girls experience high levels of stress and encounter situations associated with high risk wherein they may loose confidence in their ability to overcome hardships.

Self-esteem, the belief that there is not a discrepancy between one's ideal self-image and actual self-image (Long, 1991), is argued to be one of the most important traits in resilient youth (Gordon, 1996). Youth with high self-esteem and sense of self-efficacy report positive feelings about themselves, their social environment, and their ability to deal with life's challenges (Werner, 1992). Self-esteem is thought to serve as a psychological protective factor against the harmful effects of stress (Timko, Moos, \& Michelson, 1993) and the tendency to engage during adolescence in risky behavior, such as drug use and poor academic performance (Bell \& Suggs, 1998).

Given the resurgence of involvement in traditional activities and ceremonies in American Indian communities, adherence to traditional values and pride in one's culture provides a foundation for American Indian adolescents as they "blend the strengths of their people with the opportunities of the larger society" (Beauvais, 2000). Zimmerman and colleagues argue that enculturation, the process of learning about one's native culture, is an important resilience factor for American Indian children (Zimmerman, Ramirez, Washienko, Walter, \& Dyer, 1998). Identification with one's culture is thought to have positive developmental effects through enhanced self-esteem and conformity to cultural community norms (Phinney \& Alipuria, 1990). Studies have found that identification with, and pride in, one's ethnic group is associated with increased competence, academic achievement, and self-esteem (Martinez \& Dukes, 1997; Phinney, Cantu, \& Kurtz, 1997).

Families can play a pivotal role in the social ecology of substance use. Parental support has been found to be one of the most powerful predictors of reduced delinquency and drug use in American Indian youth (King, Beals, Manson, \& Trimble, 1992). Positive family relations discourage youth initiation into drug use (Hawkins, Catalano, \& Miller, 1992) and lend emotional support in sustaining resilience and minimizing vulnerability (Klarreich, 1998). Families can set biological risk (Schuckit, 1992) and create high-risk environments through parental or sibling substance use (Hansen et al., 1987). Increased parental supervision is also a major mediator of negative peer influence (Dishion, French, \& Patterson, 1995). These environmental risks influence socialization practices, the interpersonal dynamics of conflict, discipline, parent-child relationships, and family isolation (Kumpfer \& Alvarado, 1995).

Resilient youth seem to survive in high-risk families through their ability to adjust and cope with inconsistency and adversity (Beardslee \& Schwoeri, 1994). The task for youth in high-risk families is to: (a) avoid becoming overwhelmed by the stresses of the family, (b) maintain compassion for the family yet remain detached from family troubles, (c) develop understanding of the family's problems, and (d) receive some emotional support from well family members (Sayger, 1996). Contemporary living has required American Indian communities to develop and hone their ability to be resilient for their people to lead stable and fulfilling lives. When an American Indian family is unable to instill moral values and provide guidance and support for children, the community must take respon- 
sibility for ensuring that the family is supported in ways that improve its care for children. American Indian communities and neighborhoods both on and off the reservation can reinforce a protective sense of self-worth, identity, safety, and environmental mastery (LaFromboise \& Medoff, 2004).

There are also risk factors within the community context. One is the level of poverty and the lack of employment opportunities on the reservations. These risk factors may be further exacerbated by discrimination experienced on and near the reservation. Youth who experience race-related prejudice, discrimination, and blocked opportunities may develop oppositional cultural values that have been associated with poor outcomes, such as academic disengagement, psychosocial maladaptation, and problem behaviors at home and at school (Clark, Anderson, Clark, \& Williams, 1999; Oyserman \& Fryberg, 2005). Although parents are important mediators of children's racial understanding (Hughes \& Chen, 1999), children's exposure to influences outside of the family also prompts them to construct and reconstruct their notions about themselves as members of a racial or ethnic group (Trimble, 1988).

The analysis of predictors of resilience requires a multistage analysis. First, we need to identify youth who are demonstrating resilient responses. This is a two-step process. Initially, we will identify youth profiles that are associated with positive behavioral outcomes. Then, we need to examine the level of adversity faced by the youth. In the context of this study, we examine these adversity elements within the adolescent's household. We then identify resilient American Indian youth as those who have positive behavioral profiles while facing substantial adversity. Once the resilient youth are identified using this protocol, we examine the influence of selected individual, family, and community variables.

\section{Method}

\section{Participants}

Two hundred-twelve adolescents (115 boys and 97 girls), ranging in age from 10 to 15 years old and enrolled in fifth through eighth grades, participated in this study. They were recruited from three American Indian reservations located in the upper Midwest. The reservations, while varying in size, are similar in terms of tribal affiliation, location in rural areas, and prevalence of high levels of unemployment and poverty. Adolescents from these reservations share similar cultures, traditional language, and basic geographical regions. Fifty percent of the participants were age 11 or 12 at the time of the interview while $30 \%$ were 13 or 14 years old. Of the remaining participants, $13 \%$ were age 10 and only $6 \%$ were 15 years old. The mean of male participants was 12.1 years and of female participants was 12.2 years. Participants were nearly equally distributed across the target grades in school. Thirty-eight percent of the participants lived in single-parent households, predominantly female-headed. Approximately one-third of the participants (31\% boys and $34 \%$ girls) had never lived with their biological fathers, 32\% did not presently live with their biological father but had lived with their biological father previously, and $34 \%$ lived with their biological fathers at the time of the interview. About two-thirds of the participants $(68 \%)$ had a male caregiver present in the home.

Approximately $16 \%$ of the participants' households had incomes of $\$ 35,000$ or more per year, while $32 \%$ had incomes of $\$ 20,000-\$ 35,000$, and $36 \%$ had incomes of $\$ 10,000$ $\$ 20,000$. About $17 \%$ of their household incomes were less than $\$ 10,000$ per year. 


\section{Procedure}

To be eligible to participate in the study, adolescents had to be enrolled tribal members and at least one parent had to agree to participate. Tribal families with eligible children who lived on, or within 50 miles of, one of three reservations were included in the sample. The interviews were conducted during home visits made by one or two interviewers. All of the interviewers had tribal affiliation and were directly supervised by on-site staff. Two hundred-twelve families (85\% of all eligible families) agreed to participate in the study and completed the baseline interview survey for a prevention study (Whitbeck, Stubben, Hoyt, LaFromboise, \& Hales, 1999).

\section{Measures}

In this analysis, gender was a dichotomous variable $(0=$ male and $1=$ female $)$ and age of the youth was coded in years. A family structure variable, male in household, was a dichotomous indicator of whether there was an adult male in the household involved in supervising the youth. This could be the youth's father, stepfather, mother's live-in partner, grandfather, or any other adult male who was actively involved in a parent-like manner in the supervision of the youth.

Self-esteem was measured using items selected from the Tri-Ethnic Center's self- esteem scale (Oetting \& Beauvais, 1990/1991). This measure has been validated among minority youth, including American Indian adolescents. One dimension indicated self- esteem associated with feelings of positive self-worth (e.g., "I am proud of myself"), a second dimension tapped feelings of perceived competence (e.g., "I am able to do things well"), and the third dimension focused upon positive images in the view of other persons (e.g., "People like me"). The alpha internal consistency estimate for this measure was 0.67.

Enculturation was measured by a set of 20 items that included three basic overlapping elements: (a) participation in traditional activities, (b) identification with American Indian culture, and (c) traditional spiritual involvement. The measures for participation in traditional activities were developed through focus groups with elders and included engagement in tasks related to pow-wow celebrations, knowledge and use of traditional language, and involvement in existing practices that originated during traditional times (e.g., doing beadwork, making regalia, spear fishing, hunting). Identification with American Indian culture was measured using six items from the Oetting and Beauvais (1990/1991) American Indian Cultural Identification Scale. Traditional spiritual involvement was assessed by three global items that asked about involvement in traditional spiritual activities and the importance of spiritual values in their lives. The final enculturation measure had a Cronbach's alpha of 0.84 .

Maternal warmth was measured using the youth's reports of mother's parenting behaviors. The scale was comprised of a six-item scale made-up of questions such as the following: When you and your mom have a problem, how often can the two of you figure out how to deal with it?; How often do you talk to your mom about things that bother you? Response categories were Never, Sometimes, and Always. Internal consistency, assessed by Cronbach's alpha, was 0.65 .

Community support was a three-item index that asked the youth to rate how concerned people in their community were about children getting good grades in school, being good at playing sports, and learning their American Indian language and customs. The results were based on the youth's perception of community concern. Each question had a 3-point response scale where the youth indicated whether community members were seen as be- 
ing happy, not too concerned, or unhappy in each of these domains. The alpha reliability for this index was 0.60 .

Perceived discrimination was measured with a 10-item perceived discrimination scale designed to tap a range of potential types and sources of discrimination for youth. The questions in this scale load on three general dimensions: global discrimination, authority discrimination, and school discrimination. Global discrimination is a 5-item factor that assessed general experiences ranging from being ignored, excluded, or verbally insulted by other youth to hearing racial slurs and threats of physical harm. The second dimension, authority discrimination, consisted of three items regarding perceived discrimination by authority figures. These included being treated disrespectfully by a store clerk, hassled by police, or having adults suspect them of some type of wrongdoing because they are American Indian. The third and final dimension pertained to discrimination at school. The items on the third dimension included having teachers express surprise when they did well or teachers expecting them not to do well because they are American Indian. Internal consistency, assessed by Cronbach's alpha, was 0.80 .

Resilience was measured as a multidimensional construct. The measurement approach was to identify first a set of measures that would characterize commonly recognized dimensions of resilience, including both prosocial behaviors and the absence of problem behaviors. The prosocial measures selected here tap dimensions of school involvement, including attitudes toward school, academic plans, and current grades. The problem behaviors considered were alcohol use, other substance use, and externalizing behavior.

Developing a resilience measure is, in many respects, creating a typology of what a resilient youth should look like. In this context, it was more appropriate to use person-centered analytic approaches, like cluster analysis or latent class analysis, to empirically identify groups of youth with similar patterns of responses across the set of indicators thought to tap resilience. In effect, rather than being concerned with variable-centered approaches here, where we could establish that prosocial school involvement is correlated with low levels of problem behaviors, we wanted to explore the typologies of youth that underlie these diverse behaviors.

In the current study, we operationalized resilience by selecting a cut-point on each of the targeted behaviors that would clearly show high levels of prosocial behaviors and the absence of problem behaviors. For School Attitude, we divided youth among those who had given positive responses to each of 10 school questions, such as how well they like school, how hard they tried in school, how much they felt getting good grades in school was important, and the extent to which they were bored in school. Just under twothirds of the youth $(61.9 \%)$ gave a positive response to each of the school attitude questions. A second measure, Academic Plan, was the participant's academic plans. Here, we categorized all students who indicated their intent to complete at least a college education (58.6\% of the youth). The school measure was a self-report on grades, School Grades, where we categorized all youth who reported that their grades in school were either very good or above average $(43.3 \%)$. Finally, the absence of problem behaviors was measured by youth who had never used alcohol, No Alcohol, youth who never used any substances (e.g., marijuana, inhalants), No Substance, and youth who were below the cut-point established for the Achenbach Externalization scale (Achenbach, 1991), Not Externalize.

The pattern of these six dichotomous indicators was then examined using a latent class analysis (McClutcheon, 1985). Analyses ran using M-Plus (Muthen \& Muthen, 2000) indicated that the best-fitting model was a two latent class solution. Each of the six measures was a significant predictor of class membership and the two latent class solution appears 
Table 1. Latent Class Structure for Child Resilience

\begin{tabular}{lcc}
\hline & \multicolumn{2}{c}{ Latent classes } \\
& $\begin{array}{r}\text { Prosocial } \\
N=124\end{array}$ & $\begin{array}{c}\text { Problem } \\
N=81\end{array}$ \\
\hline School & & \\
School attitude & 0.588 & 0.065 \\
Academic plan & 0.735 & 0.359 \\
School grades & 0.614 & 0.156 \\
Behaviors & & \\
No alcohol & 0.746 & 0.188 \\
No substance & 0.503 & 0.019 \\
Not externalize & 0.891 & 0.567 \\
Class proportions & 0.605 & 0.395 \\
\hline
\end{tabular}

to provide a clear distinction between youth who show the pattern we would expect for resilient youth and those who have patterns of problem behaviors and lower school outcomes. The profiles for the two latent classes are shown in Table 1. The "pro- social" latent class, comprising $60.5 \%$ of the youth, ranks consistently higher on the school outcomes and in the absence of problem behaviors. For example, $58.8 \%$ of the prosocial latent class fully endorsed the positive school attitude items compared to $6.5 \%$ percent of the problem latent class. Similarly, nearly three-fourths $(74.6 \%)$ of the pro- social latent class youth have never tried alcohol in contrast to the $18.8 \%$ of the problem youth who have abstained. The patterns for the two empirically derived latent classes appear to show a clear distinction between youth who have patterns of behavior consistent with resilience and those who do not.

While this analysis clearly demonstrates a group of youth who are characterized by prosocial behaviors, we have not yet established the second criteria for resilience. To be considered resilient, the youth should have attained this prosocial status in the face of adversity. Youth who have prosocial outcomes in the context of a highly protective and supportive environment would not have to be necessarily resilient to reach this outcome. It could be argued, given the general level of poverty and related problems on and near reservations that all of the study youth face some proximate adversity. A more conservative approach would be to add to this assessment by looking at even more immediate risks faced by these youth, such as adversity within their household.

A total of eight measures were used to serve as potential indicators of adversity at home. One component of home adversity measures included objective and subjective assessments of economic stressors. These included whether or not the household received food stamps, the family was on some form of family assistance in the past year (e.g., TANF), or had a household income that fell below the poverty rate (based on total household income and number of persons living in the household). Parents gave a subjective assessment of financial strain by responding affirmatively to a set of items including: "Having trouble paying bills on time" and "Not having enough money to make ends meet." These items were computed into a dichotomous measure of having at least $50 \%$ of the problems.

Another dimension of adversity in the household considered here were high-risk parental behaviors. Two measures captured the history of parental problems with alcohol 
Table 2. Latent Class Structure for Family Adversity Measures

\begin{tabular}{lcccc}
\hline & \multicolumn{4}{c}{ Latent classes } \\
& $\begin{array}{c}\text { Low } \\
\text { adversity }\end{array}$ & $\begin{array}{c}\text { High poverty } \\
\text { Low parental }\end{array}$ & $\begin{array}{c}\text { Low poverty } \\
\text { High parental }\end{array}$ & $\begin{array}{c}\text { High } \\
\text { adversity }\end{array}$ \\
\hline Poverty & & & & \\
$\quad$ Food stamps & 0.060 & 0.656 & 0.043 & 0.996 \\
$\quad$ Family assistance & 0.004 & 0.757 & 0.005 & 0.994 \\
Below poverty rate & 0.071 & 0.630 & 0.287 & 0.632 \\
$\quad$ Financial strain & 0.330 & 0.651 & 0.344 & 0.778 \\
Parental problems & & & & \\
$\quad$ Drug use & 0.338 & 0.349 & 0.751 & 0.760 \\
Adult arrest & 0.167 & 0.315 & 0.954 & 0.896 \\
Alcohol treatment & 0.046 & 0.108 & 0.643 & 0.861 \\
Current binge drinking & 0.234 & 0.309 & 0.497 & 0.625 \\
Class proportions & 0.384 & 0.229 & 0.172 & 0.215 \\
\hline
\end{tabular}

or drugs. One indicator examined a history of drug use and another designated ever having had treatment for alcohol problems. A second set of indicators was about current problems. The measures probed whether there had been a recent arrest or binge drinking within the household in the past 30 days. In each instance, the measures were dichotomized to indicate that a parent (in the case of two parents, either parent) had these problems.

The pattern for these eight dichotomous indicators of family adversity was then examined with the same latent class approach as used to analyze youth resilience (McClutcheon, 1985). The M-Plus analyses indicated that the best-fitting model was a four latent class solution. Each of the eight measures was a significant predictor of class membership, and the four latent class solution appears to provide some clearly interpretable profiles of family adversity. The profiles for the four latent classes are shown in Table 2. The largest of the four latent class groups, comprising $38.4 \%$ of the families, was labeled as a lowadversity latent class. Families in this class rank consistently lower on both the economic and parental problem dimensions. For example, less than $1 \%$ of the low-adversity latent class families received family assistance, only $6 \%$ received food stamps, and less than $5 \%$ of the parents had been in alcohol treatment. Two of the latent class groups were mixed in the adversity measures. The second latent class, labeled "high poverty, low parental," had over $60 \%$ meeting the criteria for each of the family financial items but low to moderate comparative levels on parental problems. Nearly one-fourth $(22.9 \%)$ of the youth lived in households with this pattern. Approximately one in every six youth $(17.2 \%)$ were in a latent class characterized by low-poverty, high-parental patterns of responses. Here, rates for food stamps $(4.3 \%)$ and family assistance $(0.5 \%)$ are low, but parental problems range from $49.7 \%$ reporting current binge drinking to $95.4 \%$ reporting at least one adult arrest. The final latent class represents the highest adversity levels. This category, labeled "high adversity" has nearly every family getting food stamps (99.6\%) and family assistance $(99.4 \%$ ) and similarly high levels of parental problems (e.g., 62.5\% reporting current binge drinking). Just over one-fifth $(21.5 \%)$ of the families were in this group. The patterns for the four empirically derived latent classes appear to show a clear distinction between levels and patterns of family adversity. 
Table 3. Logistic Regression Predicting Youth Resilience

\begin{tabular}{lrllll}
\hline Variable & \multicolumn{1}{c}{$B$} & S.E. & Wald & Sig. & e (B) \\
\hline Gender $(1=$ female $)$ & -0.817 & 0.511 & 2.554 & 0.110 & 0.442 \\
Age & -0.468 & 0.169 & 7.681 & 0.006 & 0.626 \\
Self-esteem & 0.089 & 0.074 & 1.451 & 0.228 & 1.093 \\
Enculturation & 0.601 & 0.285 & 4.435 & 0.035 & 1.824 \\
Male in household $(1=$ yes $)$ & -0.056 & 0.480 & 0.013 & 0.908 & 0.946 \\
Maternal warmth & 0.260 & 0.112 & 5.346 & 0.021 & 1.297 \\
Lives on reservation $(1=$ yes $)$ & -0.788 & 0.540 & 2.127 & 0.145 & 0.455 \\
Community support & 0.444 & 0.250 & 3.164 & 0.075 & 1.559 \\
Perceived discrimination & -1.908 & 0.806 & 5.604 & 0.018 & 0.148 \\
Constant & 2.376 & 3.386 & 0.492 & 0.483 & 10.758 \\
\hline
\end{tabular}

\section{Results}

The data analysis was conducted using logistic regression to examine youth resilience, as defined by the latent class output. For purposes of this analysis, each family was classified in the group for which its probability was highest. To test for resilience in the face of adversity, the youth who lived in the low-adversity households were excluded from the analysis. This resulted in a sample of 126 youth who live in one of the three categories of higher-adversity households. A set of dummy variables was created to contrast the highadversity group with each of the mixed-adversity latent classes.

The basic logistic regression model is presented in Table 3. Neither living on the reservation (vs. living within 50 miles) nor having a male parent or caregiver in the house (vs. a single mother household) was significant. In terms of child characteristics, there was no significant effect for gender. However, age of child was significant. With each year of increase in age (from 10 to 15), there was an associated lowering of resilience by a multiplicative factor of 0.626 . This represents an approximate $10 \%$ decline in resiliency with each year of age. Controlling for other factors, these youth have decreasing resilience with increasing age.

Youth self-esteem did not predict resilience outcomes but other protective factors did operate as hypothesized. Maternal warmth was significantly related to outcomes that are more positive. Each unit increase in maternal warmth was associated with a 1.3 times increase in the odds of the youth being resilient. Similarly, the more enculturated the youth were, the greater their resilience. For each unit increase in enculturation, there was a 1.8 times increase in the odds of being resilient.

Perceived discrimination was a significant risk factor for lower resilience. For each unit increase in discrimination, there was a 0.148 multiplicative change in resilience. Resilience declined by approximately $40 \%$ for each increment in perceived discrimination.

Finally, there was some support for the protective effects of community support. Youth who perceived community support had higher odds for being resilient (multiplicate odds $=1.559$ ). The two-tailed significance test for this effect was only 0.07 , but the effect was in the hypothesized direction (effectively below 0.05 for a one-tailed test).

These models were also tested for the effects of the youth being in the highest adversity group versus the two intermediate groups. These analyses did not show any main effects. There were no significant differences for risk of adversity once the other background, risk, and protective measures were in the model. In addition, we tested for po- 
tential interactions between the dummy variables representing the differing mix of adversity contexts and the other independent variables in the model. We did not find any significant enhancement of the effects of risk factors (e.g., discrimination) nor diminishing of protective factors (e.g., maternal warmth, enculturation) when contrasting the highest adversity latent class to either of the mixed-adversity classes.

\section{Discussion}

The purpose of this study was to investigate the possible predictors of American Indian adolescent resilience. Importantly, the majority of the youth demonstrated resilient outcomes. The prosocial grouping, representing over $60 \%$ of the youth, had positive school outcomes and low levels of problem behaviors. Yet, one in every five youth $(21.5 \%)$ lived in high-adversity households, characterized by high poverty and high levels of parental behavioral problems. Approximately 4 of every 10 youth live in households characterized by either moderately high poverty and lower levels of parental behavior problems or lower poverty and higher levels of parental behavior problems. Combined, $61.6 \%$ of the youth live in households characterized by a moderate to high level of family adversity. It is clear from these basic distributions that a number of American Indian adolescents demonstrate resilience in the face of adversity. These findings agree with claims from earlier resilience research (Garmezy, 1993; Luthar, 1999; Werner, 1992) that adolescents can be resilient despite considerable environmental stressors, such as exposure to chronic parental substance abuse and poverty.

The analyses clearly pointed to some risk factors for resilient outcomes. The youth's reports of discrimination were associated with a marked decrease in the likelihood of a resilient outcome. Exposure to racist attitudes and behaviors appears to have a negative effect on American Indian youth. These findings add to the emerging literature that links perceived discrimination to poor mental health outcomes among racial and ethnic minority groups (Szalacha et al., 2003) and reinforce recent research that documents the pervasive impacts of discrimination on adolescent and adult American Indian depression and substance use (Whitbeck, Hoyt, McMorris, Xiaojin, \& Stubben, 2001; Whitbeck, McMorris, Hoyt, Stubben, \& LaFromboise, 2002). Perceived discrimination may have the most harmful effects on those American Indian youth with a strong cultural identity who encounter a nonaccepting majority culture (Zimmerman et al., 1998).

The finding of significantly decreasing resilience with increasing age is clearly a concern. Net of the protective effects of other factors considered in this analysis, the probability of remaining resilient declines substantially between ages 10 and 14 . It is also a concern that the other protective factors do not appear to moderate this decline. The lack of any significant interactions between age and protective factors suggests that the rate of decreasing resilience with increasing age is relatively equivalent across youth in high- adversity homes. It is possible that the cumulative effects of home adversity and increasing experiences with other adversities outside of the home as youth venture out more (e.g., increased discrimination experiences, movement to majority schools, peer pressure) combine to wear down the youth's resistance to stressors over time.

It is, however, important to recognize the important factors for youth who have maintained resilience in the face of these adversities. The strongest predictor of higher levels of resilience was enculturation. For each increment in enculturation, the youth were 1.8 times more likely to be resilient. These findings are consistent with recent research that documents the notion that greater engagement in the traditional culture may lead to more 
positive outcomes for the children (Gonzales, Knight, Birman, \& Sirolli, 2003; Huriwai, 2002; Lalonde, 2003; Zimmerman et al., 1998). In the past, researchers have suggested that an appropriate form of measurement that may determine the impact of enculturation on American Indian well-being has yet to be developed (Berry, 1994; Beauvais, 1998). Many times cultural identity measures do not incorporate crucial aspects of enculturation, such as traditional cultural practices (Oetting \& Beauvais, 1990/1991; Trimble, 1987). This research, using a measure developed in collaboration with the participating tribes, demonstrates the type of effects often hypothesized, but seldom obtained in contemporary empirical research.

There is also evidence of protective mechanisms in the home. The significantly increased likelihood of resilience with higher levels of maternal warmth suggests that the support of a parent can serve as a protective factor for youth. Cauce and her colleagues (2003) found that maternal warmth served to mitigate the combined negative effects of a delinquent peer group and father absence among urban African American adolescents (Cauce, Stewart, Rodriguez, Cochran, \& Ginzler, 2003). Many children of color are quite resilient because they learn a wide range of adaptive skills that often allows them to thrive in a multicultural society (Gardano, 1998). Sometimes, it may be difficult for an adolescent to realize that their parent is supportive because many ethnic cultures do not support the open expression of feelings. However, a review of studies by Hampson, Beavers, and Hulgus (1990) suggests that differences in communication styles between cultural groups do not necessarily have a negative impact on general family functioning.

Finally, the level of community support for prosocial outcomes is significantly associated with increased probability of resilient adaptation. This supports the research by Dubas and Snider (1993), which found that children who seem invulnerable to sustained life stress within the family have had at least one outside source of emotional assistance either from a community leader, teacher, or adult member overseeing a cooperative group. This level of support has an additive effect, complimenting the protective impact of enculturation and maternal warmth.

The finding that living either on a reservation or in an urban setting appears to have no influence on the development of resilience in American Indian adolescents attests to the salience of cultural involvement among American Indians, as well as their tenacity to maintain cultural affiliation despite continuous pressures for acculturation. This finding confirms the current trend toward American Indian cultural revitalization because it suggests that cultural involvement and community linkages still occur regardless of where a Native person lives (Snipp, 1992).

We expected to find lower levels of resilience associated with female gender, given the social and emotional demands placed upon female adolescents in this context and during this developmental period. The finding that gender does not appear to modify responses to adversity underscores the difficulty in assessing gender differences in vulnerability (e.g., comparability of stressors and their meaning).

Further research is needed to help explain why some American Indian children and adolescents are more resilient than others in adverse situations. Investigations of various combinations of stressors associated with gender roles and family and community constructs that potentially serve to buffer against negative or harmful influences are also needed. There continues to be an enormous gap between what is known about the effects of parenting on adolescents as it naturally occurs and what can be done to enhance the communication when parents struggle.

One limitation of the current study is the reliance on the perceptions of the youth for many of the key measures. For example, there was no practical way to obtain objective as- 
sessments of discrimination. It was possible, for example, that youth who were more engaged in problem behaviors may have interpreted reactions to those behaviors in school or by authorities as evidence of discrimination as opposed to reactions simply to their behaviors. Likewise, more prosocial youth could have some bias in perception of community support for their behaviors. These types of limitations are not unique to this study; much of the survey research conducted today relies on the subjective assessments of situations by the respondents. However, some caution should be exercised in the interpretation of these results because of the reliance on youth report for many of the items.

Perhaps, the most promising finding is that the protective factors identified in this analysis (enculturation, maternal warmth, and community support) are each within the domain of factors that American Indian tribes can influence. Moreover, the lack of statistical interactions among these components suggests that their effects are additive. This implies that, while making improvements in any one of these three areas would foster resilience, making additional progress in the other domains would add to the cumulative benefit. Intervention efforts that would simultaneously address enculturation, parental support, and community support for prosocial behaviors could have the greatest potential for helping youth successfully face the challenges in their day-to-day lives. If these efforts could also address the substantial risks for resilience embedded in exposure to discrimination, then further gains might be realized. While it is not likely that discrimination can be meaningfully reduced in the short run, there could be substantial benefit associated with personal, family, and community-focused efforts to provide youth with more effective coping resources.

\section{References}

Achenbach, T.M. (1991). Manual for the youth self-report and 1991 profile. Burlington: University of Vermont Department of Psychiatry.

Appleton, V.E., \& Dykeman, C. (1996). Using art in group counseling with Native American youth. The Journal for Specialists in Group Work, 21, 224-231. Beardslee, W., \& Schwoeri, L. (1994). Preventive intervention with children of depressed parents. In G.P. Sholevar (ed.), The transmission of depression in families and children: Assessment and intervention (pp. 318-339). Northvale, NJ: Aronson.

Beauvais, F. (2000). Indian adolescence: Opportunity and challenge. In R. Montmeyer, G. Adams, \& T. Gullotta (eds.), Adolescent diversity in ethnic, economic, and cultural contexts (pp. 110-140). Thousand Oaks, CA: Sage.

Beauvais, F. (1998). Cultural identification and substance use in North America-Annotated bibliography. Substance Use and Misuse, 33, 1315-1336.

Bell, C.C., \& Suggs, H. (1998). Using sports to strengthen resiliency in children. Child and Adolescent Psychiatric Clinics of North America, 7, 859-865.

Berry, J. (1994). Acculturative stress. In W. Loner \& R. Malpass (eds.), Psychology and culture (pp. 211-215). Boston, MA: Allyn and Bacon.

Blum, R., Harmon, B., Harris, L., Bergeisen, L., \& Resnick, M. (1992). American Indian-Alaska Native youth health. Journal of the American Medical Association, 267, 1637-1644.

Blum, R.W., Potthoff, S.J., Resnick, M.D. (1997). The impact of chronic conditions on Native American adolescents. Families, Systems, and Health, 15, 275-282.

Cauce, A.M., Stewart, A., Rodriguez, M.D., Cochran, B., \& Ginzler, J. (2003). Overcoming the odds? Adolescent development in the context of urban poverty. In S. Luthar (ed.), Resilience and vulnerability (pp. 343-363). New York: Cambridge University Press. 
Clark, R., Anderson, N.B., Clark, V.R., \& Williams, D.R. (1999). Racism as a stressor for African Americans. American Psychologist, 54, 805-816.

Cross, T.L. (1998). Understanding family resiliency from a relational world view. In H.I. McCubbin, E.A. Thompson, A.I. Thompson, \& J.E. Fromer (eds.), Resiliency in Native American and immigrant families (pp. 143-157). Thousand Oaks, CA: Sage.

Delgado, M. (1995). Community asset assessment and substance abuse prevention: A case study involving the Puerto Rican community. Journal of Child and Adolescent Substance Abuse, 4(4), 57-77.

Dishion, T.J., French, D., \& Patterson, G.R. (1995). The development and ecology of antisocial behavior. In D. Cicchetti \& D. Cohen (eds.), Manual of developmental psychopathology (pp. 421-471). New York: Wiley.

Dubas, J.S., \& Snider, B.A. (1993). The role of community-based youth groups in enhancing learning and achievement through nonformal education. In R.M. Lerner (ed.), Early adolescence: Perspectives on research, policy, and intervention (pp. 159-174). Hillsdale, NJ: Erlbaum.

Dunst, C.J., \& Trivette, C.M. (1994). Methodological considerations and strategies for studying the long-term follow-up of early intervention. In S. Friedman \& H.C. Haywood (eds.), Developmental follow-up: Concepts, domain, and methods (pp. 277-313). San Diego, CA: Academic Press.

Fergusson, D.M., \& Horwood, L.J. (2001). The Christchurch Health and Development Study: Review of findings on child and adolescent mental health. Australian and New Zealand Journal of Psychiatry, 35(3), 287-296.

Fleming, C., \& Manson, S. (1990). Native American women. In R. Engs (ed.), Women: Alcohol and other drugs (pp. 143-148). Dubuque, IA: Kendal/Hunt.

Gardano, A.C. (1998). Risk and resiliency factors among culturally diverse families: Implications for family psychopathology. In L. L'Abate (ed.), Family psychopathology: The relational roots of dysfunctional behavior (pp. 99-124). New York: The Guilford Press.

Garmezy, N. (1993). Children in poverty: Resilience despite risk. Psychiatry, 56, 127-136.

Gonzales, N.A., Knight, G.P., Birman, D., \& Sirolli, A.A. (2003). Acculturation and enculturation among Latino youth. In K.I. Maton, C.J. Schellenback, B.J. Leadbeater. \& A.L. Solarz (eds.), Investing in children, youth, families, and communities: Strengths-based research and policy (pp. 285302). Washington, DC: American Psychological Association.

Goodluck, C. (2002). Native American children and youth well-being indicators: A strengths perspective. Seattle, WA: Casey Family Programs.

Goodluck, C., \& Willeto, A. (2004). American Indian and Alaskan Native family resiliency: A protective rainbow. Seattle, WA: Annie E. Casey Foundation.

Gordon, K.A. (1996). Resilient Hispanic youths' self-concept and motivational patterns. Hispanic Journal of Behavioral Sciences, 18, 63-73.

Graham, B.L. (2001). Resilience among American Indian youth: First Nations' youth resilience study. (Doctoral dissertation, University of Minnesota, 2001). Dissertation Abstracts International: Section B: The Sciences and Engineering, 62, 3-B.

Hampson, R.B., Beavers, W.R., \& Hulgus, Y. (1990). Cross-ethnic family differences: Interactional assessment of white, black, and Mexican-American families. Journal of Marital and Family Therapy, 16, 307-319.

Hansen, W.B., Graham, J.W., Sobel, J.L., Shelton, D.R., Flay, B.R., \& Johnson, C.A. (1987). The consistency of peer and parent influences on tobacco, alcohol, and marijuana use among young adolescents. Journal of Behavioral Medicine, 10, 559-579.

Hawkins, J.D., Catalano, R.F., \& Miller, J.Y. (1992). Risk and protective factors for alcohol and other drug problems in adolescence and early adulthood: Implications for substance abuse prevention. Psychological Bulletin, 112, 64-105.

Heavy Runner, I., \& Marshall, K. (2003). Miracle survivors: Promoting resilience in Indian students. Tribal College Journal of American Indian Higher Education, 14, 15-17. 
Howard, M.O., Walker, R.D., Walker, P.S., Cottler, L.B., \& Compton, W.M. (1999). Inhalant use among urban American Indian youth. Addiction, 94, 83-95.

Hughes, D., \& Chen, L. (1999). The nature of parents' race-related communications to children: A developmental perspective. In L. Balter \& C. Tamis-LeMonda (eds.), Child psychology: A handbook of contemporary issues (pp. 467-490). Philadelphia, PA: Psychology Press.

Huriwai, T. (2002). Re-enculturation: Culturally congruent interventions for Maori with alcoholand drug-use-associated problems in New Zealand. Substance Use and Misuse, 37, 1259-1268.

King, J., Beals, J., Manson, S.M., \& Trimble, J.E. (1992). A structural equation model of factors related to substance use among American Indian adolescents. In J.E. Trimble, C.S. Bolek, \& S.J. Niemcryck (eds.), Ethnic and multicultural drug abuse: Perspectives on current research (pp. 253268). Binghamton, NY: Haworth Press.

Klarreich, S.H. (1998). Resiliency: The skills needed to move forward in a changing environment. In S.H. Klarreich (ed.), Handbook of organizational health psychology: Programs to make the workplace healthier (pp. 219-238). Madison, CT: Psychosocial Press.

Kumpfer, K.L., \& Alvarado, R. (1995). Strengthening families to prevent drug use in multi-ethnic youth. Salt Lake City, UT: University of Utah Health Department.

LaFromboise, T.D., Coleman, H.C., \& Gerton, J. (1993). Psychological impact of biculturalism: Evidence and theory. Psychological Bulletin, 114, 395-412.

LaFromboise, T.D., \& Dizon, M. (2003). American Indian children and adolescents. In J.T. Gibbs \& L.N. Huang (eds.), Children of color: Psychological interventions with culturally diverse youth (pp. 45-90). San Francisco, CA: Jossey-Bass.

LaFromboise, T.D., \& Howard-Pitney, B. (1995). Suicidal behavior in American Indian female adolescents. In S. Canetto \& D. Lester (eds.), Women and suicidal behavior (pp. 157-173). New York: Springer.

LaFromboise, T.D., \& Medoff, L. (2004). Sacred spaces: The role of context in American Indian youth development. In M. Weist (ed.), Community planning to foster resilience in children. New York: Kluwer Academic/Plenum Press.

LaFromboise, T.D., Oliver, L., \& Hoyt, D.R. (in press). Strengths and resilience of American Indian adolescents. In L. Whitbeck (ed.), This is not our way: Traditional culture and substance use prevention in American Indian adolescents and their families. Tucson, AZ: University of Arizona Press.

LaFromboise, T.D., Trimble, J.E., \& Mohatt, G.V. (1990). Counseling intervention and American Indian tradition: An integrative approach. The Counseling Psychologist, 18, 628-654.

Lalonde, C.E. (2003). Counting the costs of failures of personal and cultural continuity. Human Development, 46(2-3), 137-144.

Long, V. (1991). Masculinity, femininity, and women scientists' self-esteem and self-acceptance. Journal of Psychology, 125, 263-270.

Long, C.R., \& Nelson, K. (1999). Honoring diversity: The reliability, validity, and utility of a scale to measure Native American resilience. Journal of Human Behavior in the Social Environment, 2, 91-107.

Luthar, S.S. (1999). Poverty and children's adjustment. Thousand Oaks, CA: Sage.

Luthar, S.S., \& Zelazo, L.B. (2003). Research on resilience: An integrative review. In S. Luthar (ed.), Resilience and vulnerability (pp. 510-549). New York: Cambridge University Press.

Martinez, R.O., \& Dukes, R.L. (1997). The effects of ethnic identity, ethnicity, and gender on adolescent well-being. Journal of Youth and Adolescence, 26, 503-516.

Masten, A.S. (2001). Ordinary magic: Resilience processes in development. American Psychologist, 56, 227-238.

McClutcheon, A. (1985). Latent class analysis. Newbury Park, CA: Sage.

Miller-Heyl, J., MacPhee, D., \& Fritz, J.J. (1998). DARE to be You: A family-support, early prevention program. The Journal of Primary Prevention, 18, 257-285. 
Montgomery, D., Miville, M.L., Winterowd, C., Jefferies, B., Baysden, M.F. (2000). American Indian college students: An exploration into resiliency factors revealed through personal stories. Cultural Diversity and Ethnic Minority Psychology, 6, 387-398.

Muthen, B., \& Muthen, L. (2000). M-Plus users guide. Los Angeles, CA: Author.

Nelson, D.E., Moon, R.W., Holtzman, D., Smith, P., \& Siegel, P.Z. (1996). Patterns of health risk behaviors for chronic disease: A comparison between adolescent and adult American Indians living on or near reservations in Montana. Journal of Adolescent Health, 21, 25-32.

Newcomb, M.D. (1992). Understanding the multi-dimensional nature of drug use and abuse: The role of consumption, risk factors, and protective factors. In M. Glantz \& R. Pickens (eds.), Vulnerability to drug use (pp. 255-298), Washington, DC: American Psychological Association.

Oetting, E.R., \& Beauvais, F. (1990/1991). Orthogonal cultural identification theory: The cultural identification of minority adolescents. International Journal of Addictions, 25, 655-685.

Office of Juvenile Justice and Delinquency Program. (1995). Delinquency prevention works: Program summary. Washington, DC: U.S. Department of Justice, Office of Juvenile Justice and Delinquency Prevention.

Oyserman, D., \& Fryberg, S. (2005). The possible selves of diverse adolescents: Content and function across gender, race and national origin. In C. Dunkel \& J. Kerpelman (eds.), Possible selves: Theory, research, and application. Huntington, NY: Nova Science Publishing.

Pharris, M.D., Resnick, M.D., \& Blum, R.W. (1997). Protecting against hopelessness and suicidality in sexually abused American Indian adolescents. Journal of Adolescent Health, 21, 400-406.

Phinney, J., \& Alipuria, L. (1990). Ethnic identity in older adolescents from four ethnic groups. Journal of Adolescence, 13, 171-183.

Phinney, J.S., Cantu, C.L., \& Kurtz, D.A. (1997). Ethnic and American identity as predictors of selfesteem among African American, Latino, and White adolescents. Journal of Youth and Adolescence, 26, 165-185.

Rak, C.F., \& Patterson, L.E. (1996). Promoting resilience in at-risk children. Journal of Counseling and Development, 74, 368-373.

Rutter, M. (1990). Psychosocial resilience and protective mechanisms. In J. Rolf, A.E. Masten, D. Cicchetti, K.H. Nuecherlein, \& S. Weintraub (eds.), Risk and protective factors in the development of psychopathology (pp. 118-214). New York: Cambridge University Press.

Sayger, T.V. (1996). Creating resilient children and empowering families using a multifamily group process. Journal for Specialists in Group Work, 21, 81-89.

Schuckit, M.K. (1992). A clinical model of genetic influences in alcohol dependence. Journal of Studies on Alcohol, 55, 5-17.

Snipp, C.M. (1992). Sociological perspectives on American Indians. Annual Review of Sociology, 18, 351-371.

Szalacha, L.A., Erkut, S., Coll, C.G., Fields, J.P., Alarcon, O., \& Ceder, I. (2003). Perceived discrimination and resilience. In S. Luthar (ed.), Resilience and vulnerability (pp. 414-435). New York: Cambridge University Press.

Timko, C., Moos, R.H., \& Michelson, D. (1993). The contexts of adolescents chronic life stressors. American Journal of Community Psychology, 21, 397-420.

Trimble, J.E. (1987). Self-perception and perceived alienation among American Indians. Journal of Community Psychology, 15, 316-333.

Trimble, J.E. (1988). Stereotypical images, American Indians, and prejudice. In P.A. Katz \& D.A. Taylor (eds.), Eliminating race: Profiles in controversy (pp. 181-202). New York: Plenum.

Turner, S., Norman, E., \& Zunz, S. (1995). Enhancing resiliency in girls and boys: A case for gender specific adolescent prevention programming. The Journal of Primary Prevention, 16, 25-38.

Werner, E.E. (1992). The children of Kauai: Resiliency and recovery in adolescence and adulthood. Journal of Adolescent Research, 13, 262-268. 
Whitbeck, L., Hoyt, D., McMorris, B., Xiaojin, C., \& Stubben, J. (2001). Perceived discrimination and early substance abuse among American Indian children. Journal of Health and Social Behavior, 42, 405-424.

Whitbeck, L.B., Hoyt, D.R., Stubben, J.D., McMorris, B.J., \& LaFromboise, T. (in press). Enculturation and early substance use among American Indian adolescents. In L. Whitbeck (ed.), This is not our way: Traditional culture and substance use prevention in American Indian adolescents and their families. Tucson, AZ: University of Arizona Press.

Whitbeck, L., McMorris, B., Hoyt, D., Stubben, J., \& LaFromboise, T. (2002). Perceived discrimination, traditional practices and depressive symptoms among American Indians in the Upper Midwest. Journal of Health and Social Behavior, 43, 400-418.

Whitbeck, L., Stubben, J., Hoyt, D., LaFromboise, T.D., \& Hales, B. (1999). The three villages study: Results from the baseline survey, July 1999. Unpublished manuscript, Institute for Social and Behavioral Research, Iowa State University.

Zimmerman, M.A., Ramirez, J., Washienko, K.M., Walter, B., \& Dyer, S. (1998). Enculturation hypothesis: Exploring direct and protective effects among Native American youth. In H.I. McCubbin, E.A. Thompson, A.I. Thompson, \& J.E. Fromer (eds.), Resiliency in Native American and immigrant families (pp. 199-220). Thousand Oaks, CA: Sage. 